\section{JURNAL EKONOMI EFEKTIF}

ISSN : $2622-8882$, E-ISSN : 2622-9935

Jurnal Ekonomi Efektif, Vol. 3, No. 4, Juli 2021

@Prodi Manajemen Fakultas Ekonomi Universitas

Pamulang

\title{
PENGARUH KOMITMEN ORGANISASI TERHADAP KINERJA KARYAWAN PADA PT. SINAR CITRA ABADI DI JAKARTA
}

\author{
Heri Ginanjar ${ }^{1 *}$, Berliana ${ }^{2}$ \\ STKIP PGRI Sukabumi, Sukabumi, Jawa Barat, Indonesia \\ heriginanjar@stkippgrisukabumi.ac.id*, berliana@stkippgrisukabumi.ac.id
}

Manuskrip: Mei -2021 Ditinjau: Mei -2021; Diterima: Mei-2021; Online: Juli-2021; Diterbitkan: Juli-2021

\begin{abstract}
ABSTRAK
Penelitian ini bertujuan untuk mengetahui pengaruh komitmen organisasi terhadap kinerja karyawan pada PT. Sinar Citra Abadi di Jakarta. Metode yang digunakan adalah explanatory research dengan sampel sebanyak 90 responden. Teknik analisis menggunakan analisis statistik dengan pengujian regresi, korelasi, determinasi dan uji hipotesis. Hasil penelitian ini variabel komitmen organisasi diperoleh nilai rata-rata skor sebesar 3,427 dengan kriteria baik. Variabel kinerja karyawan diperoleh nilai rata-rata skor sebesar 3,858 dengan kriteria baik. Komitmen organisasi berpengaruh positif dan signifikan terhadap kinerja karyawan dengan nilai persamaan regresi $\mathrm{Y}=11,465+0,849 \mathrm{X}$, dan nilai koefisien korelasi 0,774 atau memiliki tingkat hubungan yang kuat dengan nilai determinasi 59,9\%. Uji hipotesis diperoleh signifikansi $0,000<0,05$.
\end{abstract}

\section{Kata Kunci: Komitmen Organisasi, Kinerja Karyawan}

\begin{abstract}
This study aims to determine the effect of organizational commitment on employee performance at PT. Sinar Citra Abadi in Jakarta. The method used is explanatory research with a sample of 90 respondents. The analysis technique uses statistical analysis with regression testing, correlation, determination and hypothesis testing. The results of this research variable organizational commitment obtained an average score of 3,427 with good criteria. Employee performance variables obtained an average score of 3.858 with good criteria. Organizational commitment has a positive and significant effect on employee performance with a regression equation value of $Y=11.465+0.849 X$, and a correlation coefficient value of 0.774 or has a strong level of relationship with a determination value of $59.9 \%$. Hypothesis testing obtained a significance of $0.000<0.05$.
\end{abstract}

Keywords: Organizational Commitment, Employee Performance 


\section{PENDAHULUAN}

\section{A. Latar Belakang Masalah}

Keberadaan karyawan dalam organisasi menentukan keberhasilan dan kelanjutan organisasi dalam rangka mencapai tujuan organisasi. Manajemen perlu memberikan dukungan yang kuat dalam memotivasi karyawan untuk bekerja secara profesional sehingga karyawan dapat mencapai kinerja sesuai dengan harapan organisasi mereka. Kinerja yang baik untuk individu dan kelompok menjadi pusat perhatian dalam upaya meningkatkan kinerja organisasi. Tujuan organisasi dalam mencapai produktivitas yang tinggi dengan melakukan penilaian kinerja karyawan untuk mengetahui sejauh mana karyawan mampu berperan dalam perkembangan dan pertumbuhan perusahaan demi mengikuti zaman yang mengalami perubahan dan persaingan yang sangat ketat.

Kinerja karyawan cenderung dipengaruhi oleh budaya organisasi yang berlaku. Budaya organisasi dipengaruhi oleh pemilik organisasi yang akan berpengaruh pada kinerja jangka panjang perusahaan. Budaya organisasi mempengaruhi kinerja karyawan yang dapat menaikkan koordinasi antar karyawan. Dampak budaya organisasi memberikan kontribusi secara langsung pada kinerja karyawan dalam menyelesaikan tugas-tugas yang telah dibebankan. Kehadiran budaya organisasi tentunya sangat diharapkan bagi perusahaan, agar nilai-nilai yang ada dapat dipahami dan diterapkan oleh para karyawan agar dapat tercapai kinerja yang baik dan optimal Baik buruknya sikap seorang karyawan dipengaruhi oleh komitmen yang terkandung di dalam diri karyawan tersebut, komitmen karyawan dapat digunakan untuk mengarahkan sikap perilaku demi mencapai keberhasilan organisasi. Komitmen karyawan yang berpengaruh positif terhadap kinerja merupakan dimensi perilaku yang dapat digunakan untuk menilai kecenderungan karyawan bertahan sebagai anggota organisasi.

Berdasarkan latar belakang diatas, peneliti memilih untuk meneliti mengenai kinerja karyawan dan untuk mengetahui pengaruh dari budaya organisasi dan komitmen organisasi. Sehingga peneliti mengambil judul "Pengaruh Komitmen Organisasi Terhadap Kinerja Karyawan PT. Sinar Citra Abadi di Jakarta".

\section{B. Rumusan Masalah}

1. Bagaimana komitmen organisasi pada PT. Sinar Citra Abadi di Jakarta ?.

2. Bagaimana kinerja karyawan pada PT. Sinar Citra Abadi di Jakarta?.

3. Adakah pengaruh antara komitmen organisasi terhadap kinerja karyawan pada PT. Sinar Citra Abadi di Jakarta?.

\section{Tujuan Penelitian}

1. Untuk mengetahui kondisi komitmen organisasi pada PT. Sinar Citra Abadi di Jakarta.

2. Untuk mengetahui kondisi kinerja karyawan pada PT. Sinar Citra Abadi di Jakarta.

3. Untuk mengetahui pengaruh antara komitmen organisasi terhadap kinerja karyawan pada PT. Sinar Citra Abadi di Jakarta.

\section{TINJAUAN PUSTAKA}

\section{Komitmen organisasi}

Komitmen organisasional bisa tumbuh disebabkan karena individu memiliki ikatan emosional terhadap perusahaan yang meliputi dukungan moral dan menerima nilai yang ada di dalam perusahaan serta tekad dari dalam diri untuk mengabdi pada perusahaan. Dalam suatu perusahaan sangat diperlukan adanya sebuah komitmen yang jelas dan terarah dalam mencapai keberhasilan perusahaan. Menurut Robbins (2019:35) mendefinisikan 
"Komitmen organisasi merupakan suatu keadaan dimana seorang karyawan memihak organisasi tertentu serta tujuan-tujuan dan keinginan untuk mempertahankan keanggotaan dalam organisasi”.

\section{Kinerja Karyawan}

Menurut Mangkunegara (2019:75) pengertian kinerja adalah hasil kerja secara kualitas dan kuantitas yang dicapai oleh seorang pegawai dalam melaksanakan tugasnya sesuai dengan tanggung jawab yang diberikan kepadanya

\section{METODE PENELITIAN}

\section{Populasi}

Populasi dalam penelitian ini berjumlah 90 responden PT. Sinar Citra Abadi di Jakarta

2. Sampel

Teknik pengambilan sampling dalam penelitian ini adalah sampel jenuh, dimana semua anggota populasi dijadikan sebagai sampel. Dengan demikian sampel dalam penelitian ini sampel yang digunakan berjumlah 90 responden.

\section{Jenis Penelitian}

Jenis penelitian yang dipakai adalah asosiatif, dimana tujuannya adalah untuk mengetahui atau mencari keterhubungan antara variabel independen terhadap variabel dependennya

\section{Metode Analisis Data}

Dalam menganalisis data digunakan uji validitas, uji reliabilitas, analisis regresi linier sederhana, analisis koefisien korelasi, analisis koefisien determinasi dan pengujian hipotesis.

\section{HASIL PENELITIAN}

\section{Analisis Deskriptif}

Pada pengujian ini digunakan untuk mengetahui skor minimum dan maksimum skor tertinggi, ratting score dan standar deviasi dari masing-masing variabel. Adapun hasilnya sebagai berikut:

Tabel 1. Hasil Analisis Descriptive Statistics

Descriptive Statistics

\begin{tabular}{lr|r|r|r|r} 
& N & Minimum & Maximum & Mean & Std. Deviation \\
\hline Komitmen organisasi (X) & 90 & 28 & 44 & 34.27 & 3.949 \\
\hline Kinerja Karyawan (Y) & 90 & 29 & 49 & 38.58 & 4.332 \\
\hline Valid N (listwise) & 90 & & & & \\
\hline
\end{tabular}

Komitmen organisasi diperoleh varians minimum sebesar 28 dan varians maximum 44 dengan ratting score sebesar 3,427 dengan standar deviasi 3,949. Skor ini termasuk pada rentang sakala 3,40 - 4,19 dengan kriteria baik atau setuju.

Kinerja karyawan diperoleh varians minimum sebesar 29 dan varians maximum 49 dengan ratting score sebesar 3,858 dengan standar deviasi 4,332. Skor ini termasuk pada rentang sakala 3,40-4,19 dengan kriteria baik atau setuju.

\section{Analisis Kuantitatif}

Pada analisis ini dimaksudkan untuk mengetahui pengaruh variabel independen terhadap variabel dependen. Adapun hasil pengujian sebagai berikut:

\section{a. Analisis Regresi Linier Sederhana}

Uji regresi ini dimaksudkan untuk mengetahui perubahan variabel dependen jika variabel independen mengalami perubahan. Adapun hasil pengujiannya sebagai berikut: 
Tabel 2. Hasil Pengujian Regresi Linier Sederhana Coefficients $^{\mathrm{a}}$

\begin{tabular}{|c|c|c|c|c|c|}
\hline \multirow[b]{3}{*}{ Model } & \multicolumn{2}{|c|}{ Coefficients $^{\mathrm{a}}$} & \multirow[b]{2}{*}{$\begin{array}{l}\text { Standardized } \\
\text { Coefficients }\end{array}$} & \multirow[b]{3}{*}{$\mathrm{t}$} & \multirow[b]{3}{*}{ Sig. } \\
\hline & \multicolumn{2}{|c|}{$\begin{array}{l}\text { Unstandardized } \\
\text { Coefficients }\end{array}$} & & & \\
\hline & $\mathrm{B}$ & Std. Error & Beta & & \\
\hline 1 (Constant) & 9.484 & 2.554 & & 3.713 & .000 \\
\hline Komitmen organisasi (X) & .849 & .074 & .774 & 11.465 & .000 \\
\hline
\end{tabular}

Berdasarkan hasil pengujian pada tabel di atas, diperoleh persamaan regresi $\mathrm{Y}$ $=11,465+0,849 \mathrm{X}$. Dari persamaan tersebut dijelaskan sebagai berikut:

1) Konstanta sebesar 11,465 diartikan jika komitmen organisasi tidak ada, maka telah terdapat nilai kinerja karyawan sebesar 11,465 point.

2) Koefisien regresi komitmen organisasi sebesar 0,849 , angka ini positif artinya setiap ada peningkatan komitmen organisasi sebesar 0,849 point maka kinerja karyawan juga akan mengalami peningkatan sebesar 0,849 point.

\section{b. Analisis Koefisien Korelasi}

Analisis koefisien korelasi dimaksudkan untuk mengetahui tingkat kekuatan hubungan dari variabel independen terhadap variabel dependen. Adapun hasil pengujian sebagai berikut:

Tabel 3. Hasil Pengujian Koefisien Korelasi Komitmen organisasi Terhadap Kinerja Karyawan.

Correlations $^{\mathbf{b}}$

\begin{tabular}{llr|r} 
& & $\begin{array}{r}\text { Komitmen } \\
\text { organisasi (X1) }\end{array}$ & $\begin{array}{r}\text { Kinerja Karyawan } \\
(\mathrm{Y})\end{array}$ \\
\hline Komitmen organisasi & Pearson Correlation & 1 & $.774^{* *}$ \\
\cline { 2 - 4 }$(\mathrm{X})$ & Sig. (2-tailed) & & .000 \\
\hline Kinerja Karyawan (Y) & Pearson Correlation & $.774^{* *}$ & 1 \\
\cline { 2 - 4 } & Sig. (2-tailed) & .000 & \\
\hline
\end{tabular}

Berdasarkan hasil pengujian diperoleh nilai korelasi sebesar 0,774 artinya komitmen organisasi memiliki hubungan yang kuat terhadap kinerja karyawan.

\section{c. Analisis Koefisien Determinasi}

Analisis koefisien determinasi dimaksudkan untuk mengetahui besarnya persentase pengaruh dari variabel independen terhadap variabel dependen. Adapun hasil pengujian sebagai berikut:

Tabel 4. Hasil Pengujian Koefisien Determinasi Komitmen organisasi Terhadap Kinerja Karyawan.

Model Summary

\begin{tabular}{|c|c|c|c|c|}
\hline Model & $\mathrm{R}$ & R Square & $\begin{array}{l}\text { Adjusted R } \\
\text { Square }\end{array}$ & $\begin{array}{l}\text { Std. Error of the } \\
\text { Estimate }\end{array}$ \\
\hline 1 & $.774^{\mathrm{a}}$ & .599 & .594 & 2.759 \\
\hline
\end{tabular}

Berdasarkan hasil pengujian diperoleh nilai determinasi sebesar 0,599 artinya komitmen organisasi memiliki kontribusi pengaruh sebesar 59,9\% terhadap kinerja karyawan, sedangkan sisanya sebesar $40,1 \%$ dipengaruhi oleh faktor lain yang tidak dilakukan penelitian.

\section{d. Uji Hipotesis}

Pengujian hipotesis dengan uji t digunakan untuk mengetahui hipotesis mana yang diterima.

Rumusan hipotesis: Terdapat pengaruh yang signifikan antara komitmen organisasi terhadap kinerja karyawan. 
Tabel 5. Hasil Uji Hipotesis Komitmen organisasi Terhadap Kinerja Karyawan.

\begin{tabular}{|c|c|c|c|c|c|}
\hline \multirow[b]{3}{*}{ Model } & \multicolumn{2}{|c|}{ Coefficients $^{\mathrm{a}}$} & \multirow{2}{*}{$\begin{array}{l}\text { Standardized } \\
\text { Coefficients }\end{array}$} & \multirow[b]{3}{*}{$\mathrm{t}$} & \multirow[b]{3}{*}{ Sig. } \\
\hline & \multicolumn{2}{|c|}{$\begin{array}{l}\text { Unstandardized } \\
\text { Coefficients }\end{array}$} & & & \\
\hline & $\mathrm{B}$ & Std. Error & Beta & & \\
\hline 1 (Constant) & 9.484 & 2.554 & & 3.713 & .000 \\
\hline Komitmen organisasi (X) & .849 & .074 & .774 & 11.465 & .000 \\
\hline
\end{tabular}

Berdasarkan hasil pengujian pada tabel di atas, diperoleh nilai t hitung $>\mathrm{t}$ tabel atau $(11,465>1,987)$, dengan demikian hipotesis yang diajukan bahwa terdapat pengaruh yang signifikan atara komitmen organisasi terhadap kinerja karyawan diterima.

\section{Pembahasan Hasil Penelitian}

\section{Kondisi Jawaban Responden Variabel Komitmen Organisasi}

Berdasarkan jawaban responden, variabel komitmen organisasi diperoleh ratting score sebesar 3,427 berada di rentang skala 3,40 - 4,19 dengan kriteria baik atau setuju.

\section{Kondisi Jawaban Responden Variabel Kinerja Karyawan}

Berdasarkan jawaban responden, variabel kinerja karyawan diperoleh ratting score sebesar 3,858 berada di rentang skala 3,40-4,19 dengan kriteria baik atau setuju.

\section{Pengaruh Komitmen organisasi Terhadap Kinerja Karyawan}

Komitmen organisasi berpengaruh signifikan terhadap kinerja karyawan dengan persamaan regresi $\mathrm{Y}=11,465+0,849 \mathrm{X}$, nilai korelasi sebesar 0,774 atau memiliki hubungan yang kuat dengan kontribusi pengaruh sebesar 59,9\%. Pengujian hipotesis diperoleh nilai t hitung $>\mathrm{t}$ tabel atau $(11,465>1,987)$. Dengan demikian hipotesis yang diajukan bahwa terdapat berpengaruh signifikan antara komitmen organisasi terhadap kinerja karyawan diterima.

\section{KESIMPULAN DAN SARAN}

\section{Kesimpulan}

a. Variabel komitmen organisasi diperoleh ratting score sebesar 3,427 berada di rentang skala 3,40 - 4,19 dengan kriteria baik atau setuju.

b. Variabel kinerja karyawan diperoleh ratting score sebesar 3,858 berada di rentang skala 3,40 - 4,19 dengan kriteria baik atau setuju.

c. Komitmen organisasi berpengaruh signifikan terhadap kinerja karyawan dengan persamaan regresi $\mathrm{Y}=11,465+0,849 \mathrm{X}$, nilai korelasi sebesar 0,774 atau kuat dan kontribusi pengaruh sebesar 59,9\% sedangkan sisanya sebesar 40,1\% dipengaruhi faktor lain. Uji hipotesis diperoleh nilai $t$ hitung $>\mathrm{t}$ tabel atau $(11,465>1,987)$.

\section{Saran}

a. PT. Sinar Citra Abadi harus melibatkan karyawan dalam proses pengambilan keputusan di dalam organisasi, dengan cara memberikan kesempatan yang sama bagi para karyawan untuk mengeluarkan pendapatnya di dalam organisasi.

b. PT. Sinar Citra Abadi harus selalu memberikan informasi mengenai standar pekerjaan yang sesuai dengan harapan organisasi dengan detail. Selain itu perusahaan juga dapat memberikan pelatihan dan pengembangan kepada karyawan agar para karyawan lebih memahami pekerjaannya dan dapat bekerja sesuai dengan harapan organisasi. 
c. PT. Sinar Citra Abadi dapat menyesuaikan batas waktu penyelesaian pekerjaan dengan beban pekerjaan yang diberikan dan tingkat tanggung jawab dari masingmasing karyawan.

\section{DAFTAR PUSTAKA}

Alwi, Syaffarudin. 2001. Manajemen Sumber Daya Manusia strategi keunggulan kompetitif. Yogyakarta: BPFE Yogyakarta

Bernardin, H.J. \& Russel, J.E.A. 1993. Human Resource Management anexperiental approach. Singapore: Mc Graw-Hill, Inc

Cook, John \& Wall, Toby. 1980. New York attitude measures of trust, organizational commitmentand personal need non-fulfilment. Journal of Occupational Psychology. No. 53: 39-52

Cushway dan Lodge. 2000. Budaya Organisasi. GE

Gusty Ryndian, Seno Andri. 2018. Pengaruh Budaya Organisasi Terhadap Kinerja Karyawan Dengan Komitmen Organisasi Sebagai Variabel Intervening (Studi Pada Hotel Mutiara Merdeka Pekan Baru) terbit di Jurnal Jom Fisip Vol.5

Hakim, A 2015. Effect of Organizational Culture, Organizational Commitment to Performance: Study in Hospital of District South Konawe of Southeast Sulawesi, The International Journal of Engineering and Science (Ijes), Vol.4, No.5, pp.33-41

Hasibuan, Malayu S.P. 2002. Manajemen Sumber Daya Manusia. Bumi Aksara. Jakarta.

Jufrizen, J, Muhammad Fahmi, Muhammad Ras Muis. 2018. Pengaruh Budaya Organisasi dan Komitmen Organisasi terhadap Kinerja Karyawan terbit di Jurnal Ekonomi \& Ekonomi SyariahVol.1 No.1

Kristianti, L. S., Affandi, A., Nurjaya, N., Sunarsi, D., \& Rozi, A. (2021). Pengaruh Motivasi Dan Disiplin Kerja Terhadap Kinerja Pegawai Pada Dinas Pariwisata Purwakarta. Jurnal Ilmah PERKUSI, 1(1), 101-109.

Lismiatun, L. (2018). Pengaruh Gaya Kepemimpinan Transformasional Terhadap Organizational Citizenship Behavior Dan Komitmen Organisasi Dengan Kepuasan Kerja Sebagai Peran Mediasinya (Studi Pada Karyawan PT. 3M Mining, Manufacturing, Mineshota Indonesia Departemen Supply Chain Operation). JENIUS (Jurnal Ilmiah Manajemen Sumber Daya Manusia), 1(3).

Luthans, Fred.2012. Perilaku Organisasiedisi 10.Yogyakarta:Penerbit ANDI Manery, Benyamin Richard, Regina, T, Saerang, Victor P.K., Lengkong. 2018.

McNeese-Smith, Donna. 1996. Increasing Employee Productivity, Job Satisfaction, and Organizational Commitment Hospital \& HealthServices Administration, Vol. 41: 2, p. $160-175$

Prasada, D., et al (2020). Pengaruh Etos Kerja Dan Kompensasi Terhadap Komitmen Organisasi Pada DHL Logistic Di Jakarta. JENIUS (Jurnal Ilmiah Manajemen Sumber Daya Manusia), 4(1), 51-60.

Sunarsi, D. (2019). Penerapan MSDM Strategis Dalam Upaya Meningkatkan Kemampuan Organisasi dalam menyongsong Revolusi 4.0. Jurnal Ilmiah MEA (Manajemen, Ekonomi, \& Akuntansi), $3(1), \quad 221-233$. https://doi.org/10.31955/mea.vol3.iss1.pp221-233 